\title{
Recurrent abdominal pain as a type of epilepsy among children in Diyala province/ Iraq
}

Falah Mkhaiber Mustafa (FICS) ${ }^{1}$, Mohammad Abdul Qader Alchalabi (FICS) ${ }^{2}$ and

Nadhim Ghazal Noaman $(\mathrm{PhD})^{3}$

Abstract

Background: Abdominal epilepsy is a rare condition mostly found in children, consisting of gastrointestinal disturbances caused by epileptiform seizure activity.

Objective: To study chronic about pain in relation to about to aplie.

Patients and Methods: A cross sectional study conducted in Albatool teaching hospital with a total number of 450 patient enrolled in the study suffering from chronic abdominal pain with signs and symptoms suggestive of either abdominal migraine or abdominal epilepsy and the sample selected according to electroencephalogram finding and the response to antiepileptic drugs.

Results: The incidence of abdominal epilepsy was 34 patient $(7.5 \%)$ most of them were of age group between 6-12 year, which was 23 patient (67.6). All had common symptoms of paroxysmal abdominal pain , Paleness after attack observed as a common feature (32patient), tendency to sleep after attack seen in 25patient (73.5\%).constipation and bloating together seen in 32 patient $(94.4 \%$ ) while diarrhea seen in 4 patient All of these patients investigated thoroughly for their gastrointestinal symptoms to rule out any organic diseases. All patients had constant abnormality on electroencephalogram suggestive of seizure disorder. These patients given anticonvulsant with a good response in a follow- out period of two years.

Conclusion: Abdominal epilepsy was a common health problem.

Keywords: Abdominal epilepsy, abdominal pain, children

Corresponding Author: drnadhimg@yahoo.com

Received: $14^{\text {th }}$ January 2020

Accepted: $9^{\text {th }}$ February 2020

DOI:https://doi.org/10.26505/DJM.19015160114

${ }^{1,2}$ College Pediatrician in Pediatric Department at Albatool Teaching Hospital for Maternity and Children-Diyala-Iraq ${ }^{3}$ Collage of Medicine-Diyala University -Diyala-Iraq

\section{Introduction}

Abdominal epilepsy(AE) is a rare periumbilical or epigastric, of short duration condition mostly found in children, consisting of gastrointestinal disturbances caused by epileptiform seizure activity [1]. The pain described as characteristically of a minute or two or lasting several hours. Associated gastrointestinal symptoms such as nausea, vomiting, and diarrhea found to be quite common, as well as pallor, dizziness 
and slight to marked disorientation [2]. Following such an episode, many of the patients were apathetic and lethargic for about an hour; others seemed completely exhausted and sank into a deep sleep [2].

It characterized by abdominal symptoms, electroencephalogram [EEG] abnormalities and favorable response to anti- epilepsy drugs [3]. Recurrent attacks of abdominal pain are common in childhood. In a minority of patients in which an abdominal pathology excluded, a neurological cause should be Considered. Among the diagnostic possibilities are migraine and AE [4].

Gastrointestinal presentation include recurrent abdominal pain, bloating and diarrhea nausea, vomiting, and the CNS symptoms include confusion, fatigue, headache, dizziness and fainting [5].

According to International League against Epilepsy, abdominal epilepsy considered part of simple or complex partial seizures [6]. The condition first described by Trousseau in 1868 in a boy with paroxysmal GI symptoms culminating in grand mal epileptic seizures. M.T. Moore gave in 1944, the first record of abdominal epilepsy with EEG tracings support [7]. The disease to be differentiated from $\mathrm{AE}$ is abdominal migraine. It is very difficult to differentiate $\mathrm{AE}$ and abdominal migraine especially in patients presenting with headache, because the presentations are similar. Duration of the symptoms may be used to differentiate the two; being longer in migraine than in AE [9]. Most of the patients with abdominal epilepsy usually respond to single-drug therapy but some time combination therapy may be required [10] Temporal lobe origin must be considered when the abdominal pain presents as a short paroxysmal episode followed by either awareness disturbance or automatisms, [13].

\section{Patients and Methods}

This study conducted in Albatool teaching hospital in Baaquba city, Diayla, Iraq. As cross sectional study from January 2015 during September 2019 in pediatric clinic and the ward. All severe recurrent abdominal pain whom considered as epilepsy enrolled in this study also patients whom have this signs and symptoms and diagnosed by a pediatrician. A special questionnaire used including age, gender, complaint, history of the illness, life style, food staff, physical examination, investigations ( general urine exam, general stool exam, stool for H. pylori, complete blood picture, history of drug taken, abdominal ultrasound, abdominal tomography and EEG to confirm the diagnosis.

Criteria of diagnosis:

1.Unexplained,paroxysmal gastrointestinal complaints

2.An abnormal EEG with findings specific for a seizure disorder

3.Improvement with anticonvulsant medication

Exclusion criteria:

1.Those with H. pylori infection positive 2.Those with GSE and GUE positive finding 3.Any finding in the $\mathrm{U} / \mathrm{S}$ and $\mathrm{X}$ ray and tomography

4.Patients with abdominal migraine whom responded to migraine therapy 
The EEG recorded by an EEG machine (Nihon Kohden) which made in Japan. The EEG interpreted by a neurophysiologist and the electrodes placed on the scalp according to 10-20 international system . These patients given anticonvulsant like sodium valproate, carbamazepine and phenytoin sodium and followed in a period of two years with a good response to therapy.

\section{Statistical analysis}

The data were analysis through using softwere for stastical analysis version 20 for calculating descriptive statistical analysis (frequncyu) percentage $\&$ rader.

\section{Results}

A total number of 450 patient enrolled in this study suffering from severe recurrent abdominal pain with signs and symptoms suggestive of abdominal epilepsy and the sample selected according to electroencephalogram (EEG) finding and the response to antiepileptic drugs.

The percentage of abdominal epilepsy (AE) among the studied group was 34 patient(7.5\%) most of them were of age group between 6-12 year, which was 23 patient(67.6) Table (1).

Table (1): Distribution of age and gender among the studied group

\begin{tabular}{|c||c||c|c||}
\hline Age/gender & Female No, İ(\%) & Male No.(\%) & Total No. (\%) \\
\hline \hline$<5$ year & $6(17.6)$ & $5(14.7)$ & $11(32.3)$ \\
\hline \hline 5 -9 year & $5(14.7)$ & $7(20.5)$ & $12(35.9)$ \\
\hline \hline$>10$ year & $7(20.5)$ & $4(11,7)$ & $11(32.3)$ \\
\hline \hline Total & $18(52.9)$ & $16(47)$ & $34(100)$ \\
\hline
\end{tabular}

As shown in Table (1), the number of patients below five year is $6(17.7 \%)$ in female group and 5(14.7) in male group. This is the reverse in age group between five and nine years in which the female is $5(14.7 \%)$ and male is $7(20.5 \%)$ to return again for female predominance as $7(20.5 \%), 4(11.7 \%)$ in female and male respectively in age group above ten years. The male to female ratio is 1-1.25. Table (2) shows the clinical presentation of the studied group in which all had symptoms of recurrent abdominal pain, which was centrally located in 16 patient. Headache after the attack present in $31(91 \%)$ while dizziness occurred in 19(55.8\%). Paleness after attack observed as a common feature in 32(95\%/) also the tendency to sleep after attack seen in 25patient $(73.5 \%)$.constipation and bloating together seen in 32 patient $(94.4 \%)$ while diarrhea seen in four patients $(11.7 \%)$.confusion after or during the attack occurred in $4(11.7 \%)$. 
Table (2): Distribution of clinical finding of the34 patients with abdominal epilepsy

\begin{tabular}{|c||c|c||}
\hline \multicolumn{1}{|c||}{ Clinical feature } & $\begin{array}{c}\text { Positive } \\
\text { number }(\%)\end{array}$ & $\begin{array}{c}\text { Negative } \\
\text { number }(\%)\end{array}$ \\
\hline \hline Head ache & $31(91)$ & $3(8.8)$ \\
\hline \hline dizziness & $19(55.8)$ & $15(44.1)$ \\
\hline \hline vomiting & $16(47)$ & $15(44)$ \\
\hline \hline confusion & $4(11.7)$ & $30(88)$ \\
\hline \hline Abdominal pain & $34(100)$ & 0 \\
\hline \hline nausea & $9(26.4)$ & $26(76.4)$ \\
\hline \hline Constipation & $15(44)$ & $19(55.8)$ \\
\hline bloating & $17(50)$ & $17(50)$ \\
\hline Diarrhea & $4(11.7)$ & $30(88)$ \\
\hline Sleep after attack & $25(72)$ & $2(26.4)$ \\
\hline Paleness after attack & $32(95)$ & \\
\hline
\end{tabular}

Table (3): Distribution of the abdominal pain among the 34 patient with abdominal epilepsy

\begin{tabular}{|c||l||}
\hline \hline Location of abdominal pain & No. $\%$ \\
\hline \hline Periumbilical & $16 \quad(46)$ \\
\hline \hline Both sides & $7 \quad(20)$ \\
\hline \hline Epigastric & $1(2.9)$ \\
\hline \hline Total & $34(100)$ \\
\hline
\end{tabular}

As shown in Table (3) the location of association of family member diseases with abdominal pain located centrally abdominal epilepsy was in two diseases only (periumbilical) in 16(46\%) while it was (motion sickness 14 patient and migraine in 7 $7(20 \%), 1(2.9 \%)$ in both sides and in patient as shown in Table (4). epigastric region respectively. The

Table (4): The association of family disease s with abdominal epilepsy in studied group

\begin{tabular}{||c||l||}
\hline Disease & No. \% \\
\hline \hline Motion sickness & $14(41)$ \\
\hline \hline Migraine & $7(20)$ \\
\hline
\end{tabular}

All patients had constant abnormality on shown in Table(5). EEG suggestive of seizure disorder and as 
Table (5): Distribution of electroencephalogram finding in the 34 patient with abdominal epilepsy

\begin{tabular}{|c||c||c|}
\hline EEG finding & No. & $\%$ \\
\hline \hline Generalized spike and sharp wave & 14 & 41 \\
\hline \hline Generalized abnormal epileptic discharges & 16 & 47 \\
\hline $\begin{array}{c}\text { Scattered spike wave discharges suggestive of } \\
\text { epilepsy }\end{array}$ & 2 & 6 \\
\hline \hline High voltage with generalized slowing & 2 & 6 \\
\hline \hline Total & 34 & 100 \\
\hline \hline
\end{tabular}

As shown in Table (5), the generalized abnormal epileptic discharges seen in 16 patients, generalized spike and sharp wave in 14 patients, scattered spike wave discharges suggestive of epilepsy in 2 patients and high and high voltage with generalized slowing in 2 patients. The medication used to treat these patients was the ordinary anti-epileptic drugs, as shown in table6 which was sodium valproate used with 20 patients(59\%),carbamazepine in 12 (35\%) ,phenytoin in $1(6 \%)$ and both sodium valproate and carbamazepine in $1(6 \%)$.

Table (6): Distribution of the patient with epilepsy whom were responding to antiepileptic drugs by study group

\begin{tabular}{|c|cc|}
\hline Antiepileptic drug & Number of patients & $\%$ \\
\hline \hline Sodium valproate (Depakote) & 20 & 59 \\
\hline \hline Carbamazepine (Tegretol) & 12 & 35 \\
\hline \hline Phenytoin & 1 & 6 \\
\hline \hline Depakote and Tegretol & 1 & 6 \\
\hline Total & 34 & 100 \\
\hline
\end{tabular}

The duration from the onset of the symptoms to confirmation of final diagnosis was short(less than 6 month) in 3 patients $(8.8 \%)$ while it was long in 16 of the cases (more than 12 month) .It was 15 patients in between 6 month and 12 month as in Table (7). 
Table (7): The duration of the history of recurrent abdominal pain in the study group

\begin{tabular}{||l||lc||}
\hline $\begin{array}{l}\text { Duration of the } \\
\text { symptoms }\end{array}$ & Number of patients $\%$ \\
\hline \hline$<6$ month & 3 & $(9)$ \\
\hline \hline $6-11$ month & 15 & $(44)$ \\
\hline \hline $12-23$ month & 4 & $(12)$ \\
\hline $\begin{array}{l}24 \text { month and } \\
\text { above }\end{array}$ & 12 & $(35)$ \\
\hline \hline total & 34 & $(100)$ \\
\hline \hline
\end{tabular}

\section{Discussion}

This is the first study to $\mathrm{AE}$ in diyala province in Iraq. From 450 cases in this study we found that $34(7.5 \%)$ had abdominal epilepsy (AE) this is similar to a study done by Zinkin [11] which found about 36 patient had abdominal epilepsy. While K shirsagar et al [9] found that in 150 children with chronic recurrent abdominal pain $74 \%$ of them had abdominal epilepsy. Rakesh et al found six patients with AE. in which the incidence of the disease was 0.07\%. [16] Dutta et all [3] reported four cases from India including adolescents. The most age group range from 5-13 years, which was similar to other studies $[12,16]$. The distribution of disease is the same between both genders (male -female ratio) 11.25 this was similar to other studies $[12,16]$. The most common gastrointestinal symptoms include abdominal pain, nausea, and vomiting, as in this study the main symptoms were abdominal pain (34)100\%, bloating(17) 50\%, constipation(15) $44 \%$ and vomiting(16) $47 \%$.these are similar to other studies [11, 12, 16]. The common neurological presentation include headache 31 (91\%), sleep after attack $25(72 \%)$ and paleness after attack $32(95 \%)$ lethargy and confusion4(11.7\%), dizziness $55.8 \%$ which goes nearly with a study done by Zinkin and Peppercorn which found the most common gastrointestinal symptoms to be abdominal pain, nausea and vomiting, while the most common neurological symptoms include lethargy and confusion. [12]. Disorientation during an episode of pain followed by exhaustion and sleep suggest AE in most of cases [3, 4]. Peppercorn and Herzog reviewed gastrointestinal and central nervous 
system complaints in 10 adult patients with abdominal epilepsy. They found the following abdominal symptoms: paroxysmal pain, nausea, bloating, and diarrhea. Nervous system manifestations included dizziness, headache, confusion, syncope and transient blindness, [14] and these differences probably may be due to environmental and social condition and the method studies in different countries. Hoefer et al.' [15] reported that 16 of the 31 children in their study experienced paroxysmal abdominal pain followed by post-ictal sleep as it was in our study. George H. Schade, and Helen Gofman, described 46 patients with the complaint of paroxysmal bouts of abdominal pain within 18 years [2].

The EEG findings were generalized spikes and epileptic discharges in majority of patients but it was different from other studies when the EEG findings was focal in inter temporal region. $[12,2]$.and this difference could be due to that the symptoms of epilepsy in the other studies was complex partial seizure symptoms. The abdominal pain was periumbilical in $46 \%$ this is the same in other studies $[2,12]$. The medication used to treat these patients was sodium valproate, carbamazepine and phenytoin sodium and this was the same treatment in other studies $[16,12]$ all the patients received one antiepileptic drug except one case which responded to combination of two drugs.

\section{Conclusions}

Abdominal epilepsy was a common health problem and it recommended that the pediatricians should be more aware about this disease. The abdominal epilepsy should put in mind in every patient with recurrent episodes of severe abdominal pain after other common conditions excluded.

\section{Recommendations}

Any patient with prolonged and recurrent abdominal pain should sent for EEG especially when the investigations were negative.

\section{References}

[1]Levendorf M). "Chronic abdominal pain and abdominal epilepsy". Am Fam Physician. January 2000. 61: 50.

[2]Abdominal Epilepsy In Childhood. George H. Schade and Helen Gofman, Pediatrics 1960; 25: 151.

[3]Dutta SR, Hazarika I, Chakravarty BP. Abdominal epilepsy, an uncommon cause of recurrent abdominal pain: A brief report. Gut 2007; 56:439-4.

[4]Franzon RC, Lopes CF, Schmutzler KM, Morais MI, Guerreiro MM. Recurrent abdominal pain: When should an epileptic seizure be suspected? Arq Neuropsiquiatr 2002;60:628-30.

[5]Nikolina Zdraveska, Aco Kostovski, Epilepsy presenting only with severe abdominal pain, Journal of Pediatric Neurosciences 2010; 5: 170.

[6]Benbadis, S. R. Epileptic seizures and syndromes. in E. Wyllie, ed. Neurologic clinics. Saunders, Philadelphia. 2001; 5. : 254-255.

[7]Moore MT. Abdominal epilepsy versus "abdominal migraine". Ann Intern Med. 1950 Jul; 33(1):122-33. 
[8]Siegel AM, Williamson PD, Roberts DW, Thadani VM, Darcey TM. Localized pain associated with seizures originating in the parietal lobe. Epilepsia. 1999; 40(7):845 855. [9]K shirsagar VY, Nagarsenkar S, Ahmed M, Colaco S, C Wingkar K. Abdominal epilepsy in chronic recurrent abdominal pain. Journal of Pediatric Neurosciences. 2012; 7:163-166.

[10]Tiamkao S, Pratipanawatr T, Jitpimolmard S. Abdominal epilepsy: An uncommon of non-convulsive status epilepticus. Journal of the Medical Association of Thailand. 2011; 94(8):9981001.

[11]Zinkin, N. T., and M. A. Peppercorn. 2005. Abdominal epilepsy. Best Pract.Res. Clin. Gastroenterol. [Internet] 19:263-274. [12]Bryant N. Sheeby, M.D., and Samuel C. Little, M.D.Abdominal epilepsy: The Journal of pediatrics, March 1960 Volume 56 Number 3:355-365.

[13]Henkel A, Noachtar S, Pfander M, Luders HO. The localizing value of the abdominal aura and its evolution: a study in focal epilepsies. Neurology 2002; 58:271 276.

[14]Peppercorn MA, Herzog AG. The spectrum of abdominal epilepsy in adults. Am J Gastroenterol. 1989 Oct; 84(10):1294-

6.

[15]Hoefer, P. F., Cohen, S. M., and Greeley, D. M. Paroxysmal abdominal pain: a form of epilepsy in children. J.A.M.A., 147:1, 1951. [16]Rakesh Mondal,Sumantra Sakar.ToshibadaBge A pediatric case series of abdominal epilepsy World Journal of
Pediatrics, February 2014, Volume 10, Issue 1, pp 80-82. 